\title{
A Critical Period for Experience-dependent Synaptic Plasticity in Rat Barrel Cortex
}

\author{
Kevin Fox \\ Section of Neurobiology and Center for Neural Science, Brown University, Providence, Rhode Island 02912
}

Recordings were made from neurons in layers II, III, and IV of rat barrel cortex. The animals were raised either from the day of birth (P0) or from P2, P4, or P7 with just the D1 vibrissa protruding on one side of the face and the contralateral side intact. Follicles were not ablated, but vibrissae were carefully removed by applying steady tension to the base of each vibrissa. Deprivation was continued until the day of recording (P30-P90), though in most cases vibrissae were allowed to regrow for 4-7 d prior to recording.

The area of cortex driven by stimulating the spared D1 vibrissa was found to be enlarged in uni-vibrissae animals, but the characteristic anatomical map of the barrel field, defined by cytochrome oxidase staining, retained its normal form. In animals deprived from P0, layer IV cells outside the D1 barrel responded with short latencies (5-10 $\mathrm{msec}$ ) to D1 stimulation, a condition never observed in normally reared animals. Short-latency responses to stimulation of regrown, deprived vibrissae were still present in layer IV despite the deprivation.

Plasticlty decreased rapidly in layer IV between PO and P4 as judged by two measures: first, the percentage of cells in neighboring barrels that showed short-latency responses to $\mathrm{D} 1$ fell from $30 \%$ in P0 deprived animals to $18 \%$ in $\mathrm{P2}$ and $13 \%$ in P4 deprived animals. Second, the percentage of cells in barrels surrounding D1 with larger responses to D1 stimulation than to stimulation of their anatomically related vibrissa also fell from $37 \%$ in P0 to $23 \%$ in P2 and $12 \%$ in P4 deprived animals. The percentage of "shifted cells" showed no further reduction in P7 deprived animals $(14 \%)$.

Plasticity in layers II and III showed little sign of decreasing between P2 and P7 after an initial drop between P0 and P2. Therefore, deprivation started at P4 and P7 had a far greater effect on layers II and III than on layer IV. In animals deprived from P4 onward, not only were responses to D1 stimulation greater in barrels neighboring $\mathrm{D} 1$ (in layers II/III), but responses were smaller to principal vibrissa stimulation. This suggests increased lateral transmission from the "experienced" barrel and a failure of vertical transmission within the "deprived" barrels.

These results show that changes in the balance of ex-

Received Sept. 18, 1991; revised Dec. 11, 1991; accepted Dec. 18, 1991.

I am grateful to Paula Krueger and Cheryl Pulaski for technical assistance, and to Barry Connors and John Donoghue for criticism of the text. This work was supported by NIH Grant NS 27759.

Correspondence should be addressed to K. Fox, The Section of Neurobiology and Center for Neural Science, Box G, Brown University, Prnvidence, RI 02912.

Copyright $\oplus 1992$ Society for Neuroscience $0270-6474 / 92 / 121826-13 \$ 05.00 / 0$ perience acquired through vibrissae can affect development of connectivity in the barrel cortex. The main locus of plasticity is cortical when deprivations are started at P4 and beyond. Cells in layers II and III showed greater plasticity at all ages and appeared to have a longer critical period for experience-dependent plasticity than did cells in layer IV.

Sensory cortical areas lend themselves well to investigation of cortical plasticity. The effect of monocular deprivation on visual cortex is probably the most used model for studying experiencedependent synaptic plasticity in the cerebral cortex (Wiesel and Hubel, 1963). Closing one eye in early life causes the visual cortex to develop connections heavily biased toward the experienced eye at the expense of the deprived eye. It has been demonstrated that an imbalance in visual experience, and spontaneous activity, in the visual pathway is the cause of the imbalance in the cortical representation of the two eyes in monocularly deprived cats (Wiesel and Hubel, 1965; Chapman et al., 1986). It is of importance to know whether the mechanisms underlying normal development and synaptic plasticity in visual cortex are common to all cortical areas, or whether visual cortex must be treated as a special case. To this end, in this study, developmental plasticity was investigated in the rat somatosensory cortex.

Rat barrel cortex offers several advantages over visual cortex for studying experience-dependent plasticity. First, an anatomical map of the periphery exists in rat barrel cortex that normally corrclates so strongly with the receptive field of the cell that it provides a means of predicting what the cells' normal inputs would have been in the absence of deprivation. By contrast, in visual cortex it is not possible to know whether a cell responding to the left eye, for example, would have responded to that eye anyway despite the monocular occlusion. Second, the columnar organization and receptive field properties are simpler in barrel cortex, which should facilitate identification of the pathways involved in plasticity. Finally, a great deal of information is becoming available on the molecular and biochemical development of rodent cortex, to add to the substantial knowledge accumulated about its anatomical development (Woolsey, 1991). The critical period for experience-dependent plasticity has not been studied in this area before, however, and was therefore the subject of the present investigation.

Previous experiments on plasticity in the somatosensory system have not always addressed the question of experience-dependent plasticity in the cerebral cortex. Deprivations in the somatosensory system have generally been induced by lesions, either of nerves or vibrissae follicles, and this is equivalent to 
eye enucleation or retinal lesion in the visual system and is quite a separate phenomenon from monocular deprivation (Kaas, 1991). Second, it has always been ambiguous whether changes in the somatosensory cortcx are a reflection of changes occurring at a thalamic, brainstem, or primary afferent level or whether they really represent a reorganization of cortical connectivity. This is much less of a problem when interpreting the results of monocular deprivation experiments since the first cells exhibiting binocular receptive fields in the visual pathway occur in the cortex.

However, Hand (1982) and Simons and Land (1987) have shown that trimming vibrissae rather than lesioning follicles can cause changes in cortical organization. This procedure appears just to change the balance of activity in the pathways from the vibrissae to the cortex, in the same way that monocular deprivation alters the balance of activity from the two eyes to the cortex. It can therefore be used to study experience-dependent plasticity in the somatosensory system independent of the complicating effects of nerve degeneration, cell death, and primary afferent regeneration (Waite and Cragg, 1982; Hamori et al., 1986; Rhoades et al., 1987). In this article, the critical period for experience-dependent synaptic plasticity is examined in individual layers of the barrel cortex. The results expose different critical periods for different cortical layers and also provide some insights into the pathways involved in the plasticity.

\section{Materials and Methods}

Subjects. Long-Evans rats of known age were used in all experiments. Rats were reared in litters of 10 with experienced mothers. Recordings were made between 30 and $90 \mathrm{~d}$ of age (P30-P90). Results are reported for 1040 cells recorded from 59 rats, 12 normally reared and 47 deprived of all but the D1 vibrissa from P0 (15), P2 (10), P4 (14), and P7 (8).

Deprivation. Mothers were monitored every $12 \mathrm{hr}$ around parturition in order to ensure that deprivation started at or around $12 \mathrm{hr}$ after birth (for the animals deprived from P0 onward). This usually allowed time for the rat pups to receive colostrum before being treated. Animals younger than $7 \mathrm{~d}$ were anesthetized by cooling in a $4^{\circ} \mathrm{C}$ refrigerator. Cooling by direct contact with ice was not attempted in order to avoid cold lesions. Beyond $7 \mathrm{~d}$ of age, Metofane methoxyflurane anesthesia was used instead (Pitman Moore, Mundelein, IL). Animals were exposed to Metofane for $1-4$ min dependent on age, which provided anesthesia for 3-5 min after returning them to the air.

Using an operating microscope, vibrissae were gently pulled from the face by applying slow, steady tension. Vibrissae were not plucked rapidly, as this tended to remove some of the follicle, too, A steady pull removed the hair only. In P0 animals this technique did not result in gross damage when done as described, as there was little resistance to vibrissae removal. This method does not damage the follicle (Hand, 1982). All vibrissae were removed from one side of the face, sparing the D1 vibrissa, starting at ages $\mathrm{P} 0$ (12 hr postnatal), P2 (48 hr), P4, and $P 7$. Vibrissae were pulled every other day, though for animals where deprivation was started in the first week the vibrissae generally did not regrow until the third day after the first deprivation. Vibrissae pulling was continued until the day of recording, though in most cases vibrissae were allowed to regrow starting 4-7 d before recording. In-growing vibrissae and regrowing vibrissae that had not yet broken through the skin were generally left until they emerged before removal.

On starting vibrissa pulling on a given day, our technique was to remove obvious vibrissae first, then to search systematically through $\delta$, the $E$ row from 1 to $6, \gamma$, the D row from 2 to 6 , and so forth until A4 was reached. As a final check, the head was rotated to view the vibrissae from above, which was useful for detecting any clear or uncolored vibrissae that had been missed the first time. The small vibrissae at the front of the nose were not removed.

Controls. Littermates of the pups deprived starting at $P 0$ were subject to the same once-every-second-day routine of brief anesthesia and recovery, but not vibrissae removal.

Surgery. Surgery was performed on animals between 30 and $90 \mathrm{~d}$ of age to prepare them for neuronal recording. Animals were induced with halothane or Metofane, and anesthesia was maintained with an intraperitoneal injection of $30 \%$ urethane at a dose of $1.5 \mathrm{gm} / \mathrm{kg}$ whole body weight. Supplementary doses of 60-90 mg were administered as necessary. Lidocaine (Phoenix, St. Joseph, MO) was injected subcutaneously around wound margins, and viscous cetacaine (Cetylite Inc., Pennsauken, NJ) applied topically in the ears. The animals were located in a stereotaxic apparatus (Narashige, Tokyo, Japan), and their body temperature was maintained using a heating pad at $35.5-36.2^{\circ} \mathrm{C}$ under the feedback control of a rectal thermistor.

The surgery was performed carefully to minimize trauma to the cortex. An area of skull was removed extending 1-5 mm posterior to bregma and $4-6.5 \mathrm{~mm}$ lateral to the midline. If excessive dural bleeding was encountered, the middle meningeal artery was tied off with a fine hair. Small $(50 \mu \mathrm{m})$ holes were made in the dura to introduce the electrode, one for each new penetration. This method was successful in reducing damage to the superficial layers of the cortex that could result from removing a larger area of dura. Leaving the dura largely intact increased the encounter rate for cells in superficial layers and seemed to maintain their responsiveness to tactile stimuli.

Recordings and electrodes. Single-barrel carbon fiber electrodes were made as described previously (Armstrong-James et al., 1980). Signals were amplified and filtered through a fourth-order Butterworth bandpass filter set at $600 \mathrm{~Hz}$ to $8 \mathrm{kHz}$ and two $60 \mathrm{~Hz}$ notch filters (Digitimer, Welwyn Garden City, UK). Spikes were discriminated using a voltage window detector. Validity of single-cell recording was checked by monitoring the spike waveform on a digital oscilloscope (Hitachi VC-6025).

Stimulus. Stimuli were generated using a piezoelectric bimorph wafer driven by a high-compliance stimulus isolator (DS2, Digitimer). Contact with the vibrissa was made via a stiff glass capillary attached to the piezoelectric device. The stimulus was arranged to be as similar to that described by Armstrong-James and Fox (1987) as possible. Therefore, the stimulus driver and damping were adjusted to give a $200 \mu \mathrm{m}$ deflection at $10 \mathrm{~mm}$ from the face, a $1 \mathrm{msec}$ rise time, and oscillations damped out within $1.6 \mathrm{msec}$ of reaching peak deflection. The stimulus duration was $10 \mathrm{msec}$ delivered at a $1 \mathrm{sec}$ repetition interval.

Sampling and analysis. Having introduced the electrode below the pia, the penetration was allowed to stabilize for 5-10 min. An effort was made on each penetration to sample cells in the first $200 \mu \mathrm{m}$. Thereafter the electrode was moved approximately $150 \mu \mathrm{m}$ between recording sites to a depth of generally no more than $700 \mu \mathrm{m}$. A small $50 \mu \mathrm{m}$ lesion $(2.2 \mu \mathrm{A}, 10 \mathrm{sec}$, tip negative) was made at the end of the track before driving down to layer $\mathrm{V}$ to record from cells firing bursts of action potentials. This size lesion is too small to affect somatotopic organization (see Armstrong-James et al., 1991). The burst rate was measured to give an estimate of anesthetic depth, which was moderate but not deep. Anesthesia was adjusted to keep the average burst rate between 0.7 and $2 \mathrm{~Hz}$ (a burst is a group of sequential spikes with interspike intervals not falling below $150 \mathrm{msec}$ ). Bursts of spikes in layer $\mathrm{V}$ cells are synchronous and produce a synchronized delta frequency EEG (Armstrong-James and Fox, 1988). The level of anesthesia used here is slightly deeper than that used by Armstrong-James and Fox (1987) and the hind limb reflex is present but not brisk under such conditions.

Poststimulus time histograms (PSTHs) and latency rasters were produced on line using a CED 1401 (Cambridge Electronic Dcsign, Cambridge, UK). PSTHs and latency histograms were analyzed off line and the magnitude of response and modal latency noted. The response for each cell was defined as the number of spikes produced from 5 to 50 msec after the stimulus onset minus the spontaneous activity. Spontaneous activity was assessed over the $50 \mathrm{msec}$ preceding the stimulus. In a standard trial 50 stimuli were applied. For full details of what is considered as a response, see Armstrong-James and Fox (1987).

In this report, the latency of response means the modal latency. The modal $1 \mathrm{msec}$ bin of the latency histogram needed to contain at least three counts after 50 stimuli had been delivered for the measurement to be used in the analysis.

Definitions. The principal vibrissa for each cell was defined as the topologically related vibrissa for the barrel in which the cell was located; that is, the D2 vibrissa would be the principal vibrissa for a cell located in the D2 barrel. In order to make comparisons between the responses evoked in a cell by stimulating the D1 vibrissa and the principal vibrissa, the fraction $F$ was calculated, where

$$
F=\mathrm{D} 1 /(\mathrm{D} 1+P)
$$

and $\mathrm{Dl}$ is the response (see above) produced by stimulating D1 50 
A

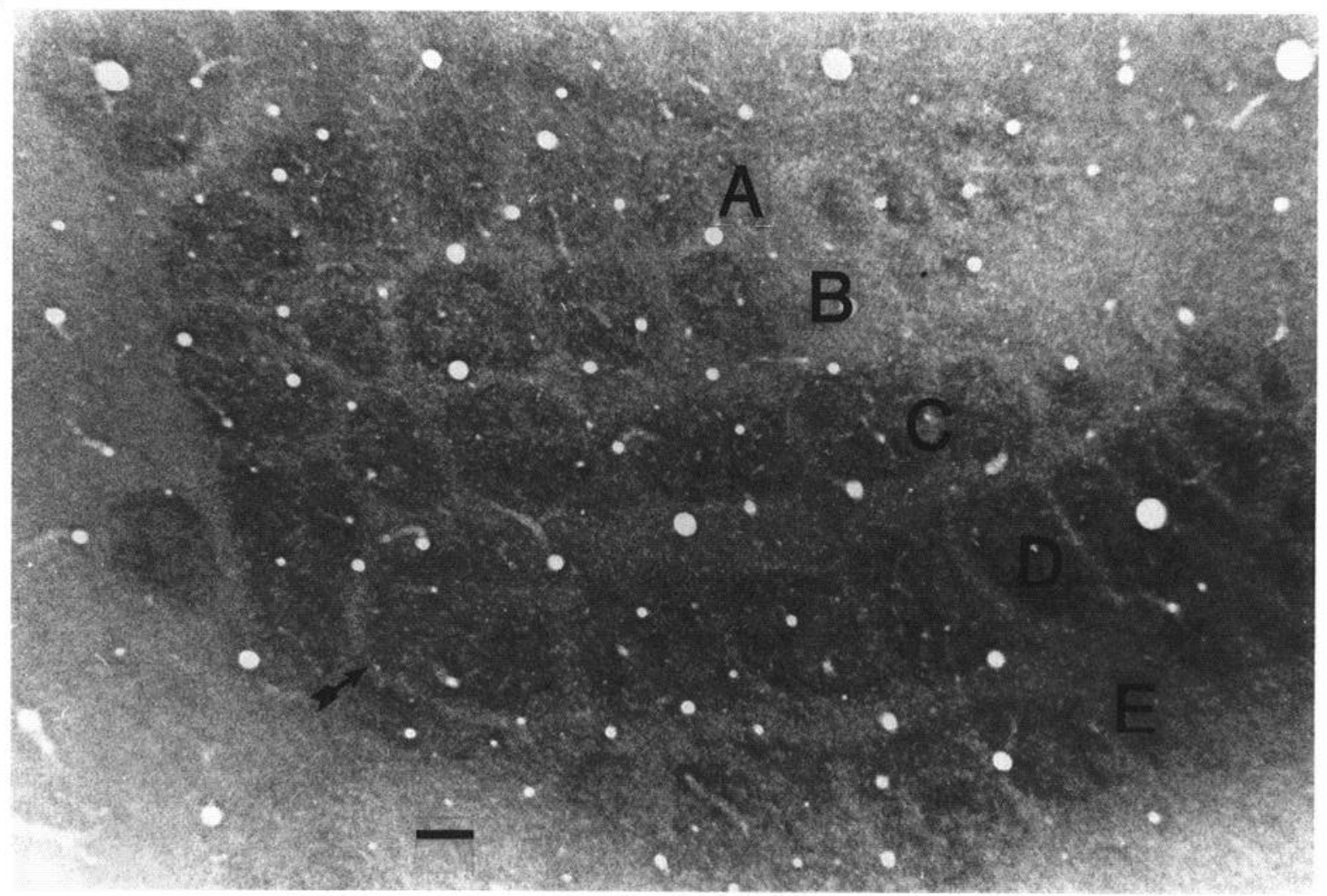

B

SOMATOSENSORY CORTEX

OF THE RAT.

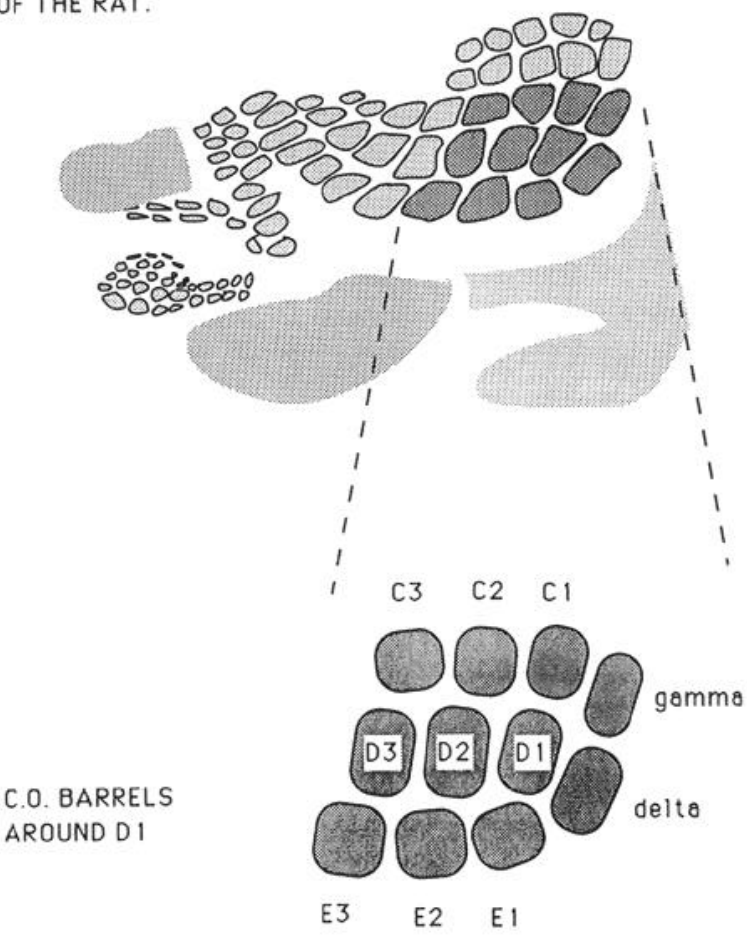

Figure 1. A, Photomicrograph of a horizontal flattened section through barrel cortex of an animal deprived of all but D1 vibrissa input from $\mathrm{P} 0$ up to the age of death. The section is stained using the $\mathrm{CO}$ technique. Note the enlarged D1 barrel (arrow). Scale bar, $150 \mu \mathrm{m}$. B, Schematic representation of the barrel cortex. A representative cortical section was mapped using a graphics program. The barrels immediately surrounding D1 have been extracted and their shapes simplified slightly. The simplified map appears in Figures 2 and 4. 

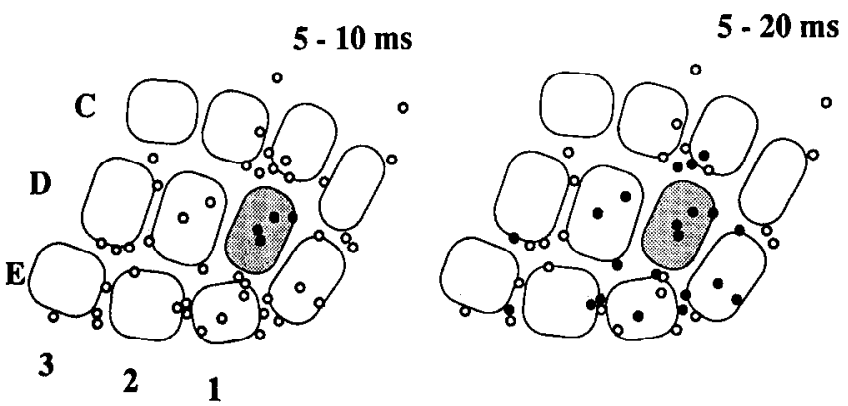

5 - $20 \mathrm{~ms}$

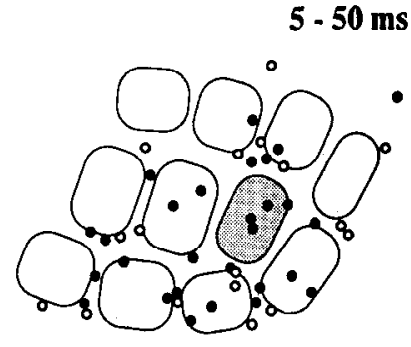

PQ LIV -DI

5 - $10 \mathrm{~ms}$

5 - $20 \mathrm{~ms}$

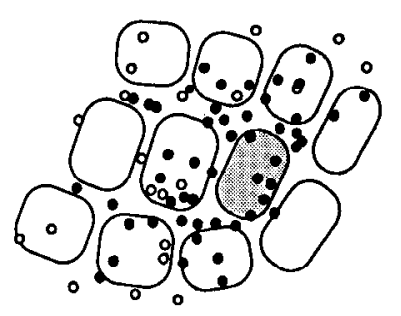

5 - $50 \mathrm{~ms}$

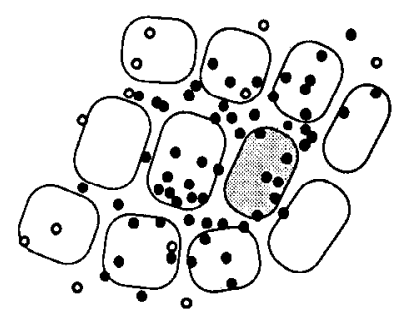

Figure 2. Effect of deprivation on somatotopy in layer IV. Top, Location of 47 penetrations made in control animals with respect to the CO-defined barrel field map (see Fig. 1). Each point marks one penetration identified from a small focal lesion made in layer IV of the cortex at the end of recording. Solid circles represent locations of penetrations containing at least one cell in layer IV that responds to stimulation of the D1 vibrissa within 5-10 msec (left), 5$20 \mathrm{msec}$ (center), and 5-50 msec (right). Open circles represent cells that did not respond within that time limit. Note that the maps are cumulative, so cells responding at $5-10 \mathrm{msec}$ are necessarily included again in the 5-20 $\mathrm{msec}$ map. Bottom, Location of 77 penetrations as they pass through layer IV made in animals deprived of all but the DI vibrissa from P0. Note that the cells responding at short latencies to D1 vibrissa stimulation are not distributed solely in the D1 barrel (shaded barrel). times, and $P$, the response evoked by stimulating the principal vibrissa 50 times. The index gives a value between 0 and 1 as a measure of the relative dominance of the $D 1$ to principal vibrissa. A value of 1 indicates that the cell only responds to D1 and not its principal vibrissa, 0.5 indicates equal influence of D1 and the principal vibrissa, and so forth. This is a measure similar to the quantitative ocular dominance index used by Ramoa et al. (1988).

For some types of analysis it was convenient to divide the cortex into four areas, D1 barrel, near side and far side of neighboring barrel, and beyond far side. The DI barrel consisted of the cytochrome oxidase (CO)-defined Di barrel and half of the septal area nearest to D1. The D1 area was defined by anatomical features in layer IV but was considered to project radially up and down through the cortex as well. The second area was the nearest half of all the barrels immediately neighboring the DI barrel (near side of neighbors). The neighboring barrels for D1 are $\delta, E 1, E 2, \gamma, D 2, C 1$, and $C 2$ (see Fig. 1). The third area was the far half of the same barrels neighboring $\mathrm{D} 1$, including half of the septal area between them and their neighbors (far side of neighbors). The fourth area was the rest of the cortex beyond the far side of the immediate neighboring barrels. The properties of cells were analyzed in relation to the area of the cortex in which they were located.

Lesions and histology. The position of each electrode track within the barrel field was marked by passing $2.2 \mu \mathrm{A} \mathrm{DC}$ for $10 \mathrm{sec}$ (tip negative) through the electrode tip when it was in layer IV (estimated during the experiment by short-latency responses and depth below pia $[500-700$ $\mu \mathrm{m}])$.

Animals wcre deeply anesthetized before perfusion through the heart with phosphate-buffered saline followed by $4 \%$ paraformaldehyde and then $10 \%$ sucrose in $4 \%$ paraformaldehyde. The brain was removed, carefully flattened between two microscope slides, and left in $20 \%$ sucrose (in $4 \%$ paraformaldehyde) overnight. Frozen horizontal sections. were cut at $50 \mu \mathrm{m}$ the next day, and the sections were left to wash in phosphate-buffered saline for $1 \mathrm{~d}$ before reacting for cytochrome oxidase (CO) (Wong-Riley, 1979).

The location of each cell was then reconstructed within the $\mathrm{CO}$ defined barrel field by postmortem examination. A record of the position of each penetration was made using a microscope with a camera lucida attachment. The position of the cells was then logged on a standardized barrel map stored on computer. Cross-sectional areas of barrels were measured from camera lucida drawings of flattened horizontal sections by tracing around the borders of the $\mathrm{CO}$-stained barrels using a digitizing tablet and SIGMA SCAN software (Jandel, San Rafael, CA).

\section{Results}

\section{Changes in histology}

The barrel field appeared well defined in D1-spared animals, and the size and form of the barrel field were consistent between animals. In one-third of the animals deprived of all but the D1 vibrissa from P0 (5 of 15 ), the D1 barrel was slightly enlarged compared to surrounding barrels and to the D1 barrel in control animals. An example of an enlarged D1 barrel is shown in Figure 1. Note that the barrel size is defined by $\mathrm{CO}$ staining. Barrels were of normal size in animals deprived from P2 to P7 (32 of 32).

To quantify these observations, the cross-sectional areas of CO-defined caudal barrels (D1-D3, C1-C3, E1-E3) were measured at greatest girth in normal and D1-spared animals. The average caudal barrel area in normal animals was $1.43 \pm 0.23$ $\times 10^{5} \mu \mathrm{m}^{2}$, which was not significantly different from barrel area in D1-spared animals (1.5 $\left.\pm 0.36 \times 10^{5} \mu \mathrm{m}^{2}\right)$, suggesting that barrels were the same size in normal and D1-spared animals. However, a comparison of the means hides the fact that in five of the D1-spared animals the DI barrel was visibly larger. The average area for this subgroup was $2.72 \pm 0.24 \times 10^{5} \mu \mathrm{m}^{2}$, which was $35 \%$ larger than the largest barrels seen in normal animals. Therefore, deprivation occasionally altered barrel size if started at $\mathrm{P} 0$, but more often had no effect.

\section{Changes in response properties}

A total of 254 cells were recorded from 77 penetrations made in the barrcl cortex of 15 animals deprived of all but the D1 vibrissa on $\mathrm{P} 0$. In the following analysis these cells are compared with results from 159 cells recorded in 47 penetrations made in the control group. 


\section{Effect of Rearing with D1 Vibrissa Only on Response Latencies to Stimulation of D1 in Layer IV.}
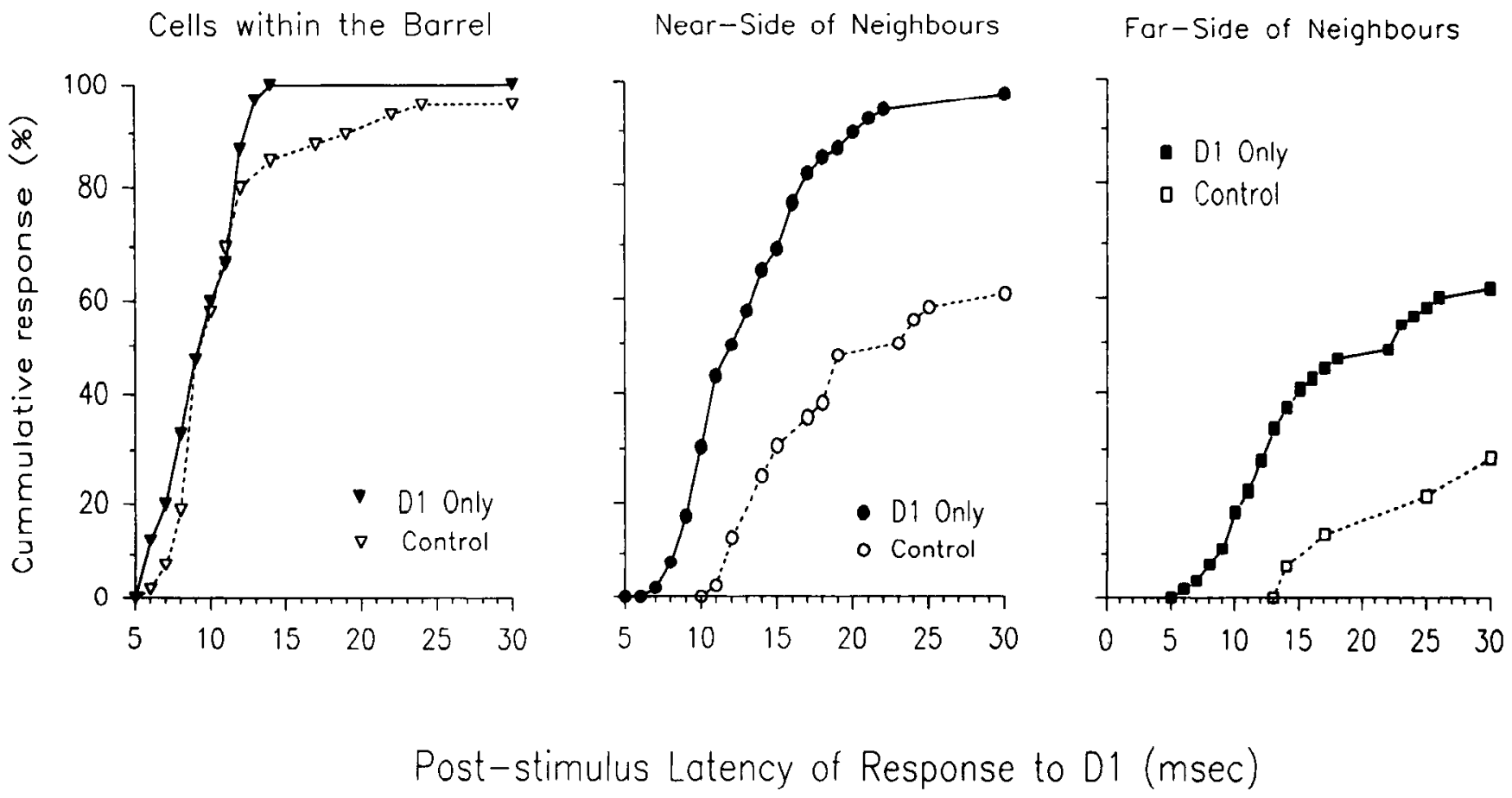

Figure 3. Effect of deprivation on response latencies in layer IV to "experienced" vibrissa. Results from 121 P0 and 66 control layer IV cells are represented in three graphs grouped according to the location of the cells in the barrel field. Left. Cumulative distribution of latency of response for cells located in the D1 barrel recorded from control (open triangles) and D1-spared (solid triangles) animals. Note that this population of cells have similar response times. Center, Cumulative distributions of response latencies for cells located on the near side of barrels immediately surrounding D1. Note that the population of cells in D1-spared animals (solid circles) have far shorter latencies than controls (open circles), and a greater percentage respond. Right, Cumulative distributions for cells located on the far side of the barrels neighboring D1. Again, the population of cells respond more quickly in D1-spared (solid squares) than control animals (open squares), and more cells respond.

\section{Response latencies in layer IV}

In order to examine the spatial distribution of cells responding to D1 (the D1 domain), the location of each penetration was marked by a small focal lesion in layer IV, which could be referred to the $\mathrm{CO}$ map of the barrels post-mortem. The location of the penetration was then transferred to a stylized map of the barrel field that was derived as shown in Figure $1 B$. This method allows one to see whether the D1 domain is enlarged in D1spared animals. Since domain size is also a function of response latency (Armstrong-James and Fox, 1990), latency was also taken into account in the analysis. The results arc presented in Figure 2 for control and P0 deprived animals.

In common with a previous study (Armstrong-Iames and Fox, 1990), the earliest responses of any cortical cells to stimulation of the vibrissae occurred in layer IV $6 \mathrm{msec}$ after the stimulus onset. In control animals, most cells in layer IV (60\%) responded within $10 \mathrm{msec}$ of the stimulus onset to at least one vibrissa (i.e., the modal latency was less than $10 \mathrm{msec}$ ).

Figure 2 shows the location of cells in layer IV responding within 5-10 msec of stimulating the D1 vibrissae for the group of control animals. It is noticeable that short-latency responses to D1 stimulation are confined to the D1 barrel in control animals. Longer-latency responses to Dl stimulation (>10 $\mathrm{msec}$ ) occur outside the DI barrel. These findings for 66 layer IV cells in control animals are supported by recordings from 106 other layer IV cells in two previous studies (Armstrong-James and Fox, 1987, 1990), which show results similar to those depicted in Figure 2.

Animals raised from P0 with only the D1 vibrissa exhibited a markedly different spatial distribution of short-latency (5-10 $\mathrm{msec}$ ) responses, however. Short-latency responses to D1 were found in all barrels adjacent to the D1 barrel; as can be seen from Figure 2, they occurred sporadically, interspersed with more slowly responding cells. The farthest lateral extent of the short-latency responses was not systematically detcrmined; however, one cell was found in the D3/E3 septum with a latency of $8 \mathrm{msec}$, showing that they can occur beyond the barrels immediately neighboring $\mathrm{Dl}$.

In D1-spared animals, most of the cells (70\%) had responded to stimulation of D1 within $20 \mathrm{msec}$. By $50 \mathrm{msec}$ a further $11.5 \%$ had responded but without increasing the area of the barrel map over which responses were found. If the 30-50 msec responses are taken into account, the cortical area over which responses to $D 1$ are found is approximately the same in control and D1-spared animals. The major difference between the two groups is that the likelihood of any given cell responding to Dl within that area is greater in D1-spared animals $\left(p<0.001, \chi^{2}\right.$ 
5-10 ms

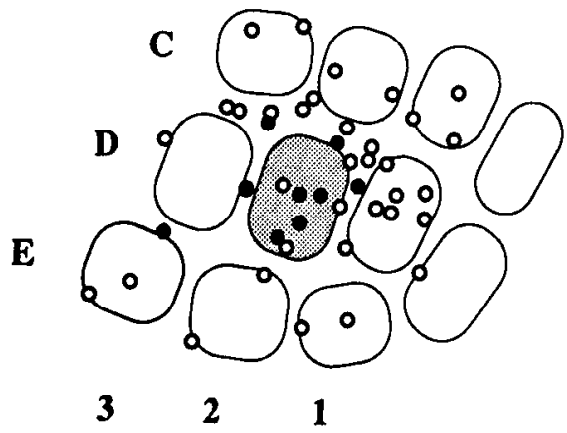

5-20 ms

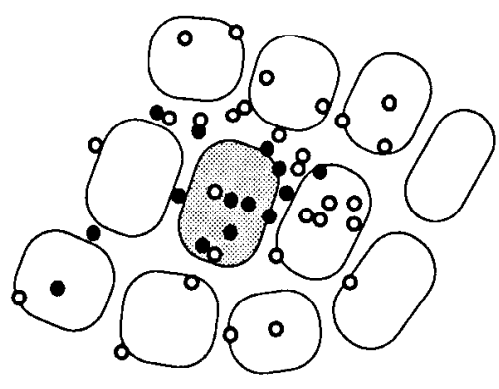

5-50 ms

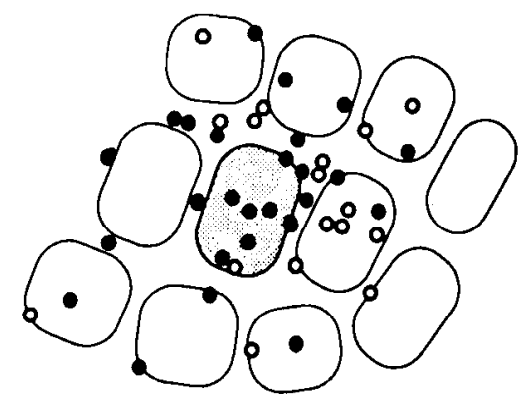

Figure 4. Lack of enlargement of the D2 domain in animals deprived of all vibrissae (including D2) but D1 from P0: location of 44 penetrations made in barrel cortex where cells were tested for responses to D2. Details are as in Figure 2. Note that the short-latency responses are largely confined to the D2 barrel (shaded barrel), except for one unusual cell between $E 3$ and $D 3$, and the longer-latency responses radiate out from D2 at successively greater times in a fashion similar to control responses (see Fig. 2). There is a slight tendency for excitation not to invade D1.

test). On the other hand, the domain size of DI is larger in layer IV of D1-spared animals if the analysis is confined to a consideration of responses occurring within the 5-10 and 5-20 msec time windows.

The differences between normally reared and D1-spared animals, described above, were quantified by dividing the barrel field into four areas (see Materials and Methods). The latency of response to stimulation for the D1, near side, and far side areas of the barrel field is plotted in the cumulative distributions shown in Figure 3. In layer IV, the latency of response to principal vibrissa stimulation was similar for cells recorded in control and D1-spared animals. The major differences occur in the near and far side oif the barrels neighboring D1. In the D1spared animals, responses were quicker and more likely to occur, with $50 \%$ of cells on the near side of barrels neighboring D1 responding within $11 \mathrm{msec}$ (compared with $19 \mathrm{msec}$ for normal animals). In the D1-sparcd animals, on the near side $100 \%$ of the cells responded within $30 \mathrm{msec}$, whereas only $60 \%$ responded at all in control animals. A similar pattern is repeated for cells located on the far side of the barrels neighboring Dl but at longer latencies (see Fig. 3 caption).

Responses occurring within $10 \mathrm{msec}$ of stimulation were never found in the barrels neighboring D1 in control animals. This is similar to the result found by Armstrong-James and Fox (1987), where just $2 \%$ of fast responses were found outside the topologically related barrel (principal barrel). In contrast, in D1spared animals, cells showing responses occurring within 10 msec comprised $30 \%$ of all cells located on the near side and $20 \%$ all of cells located on the far side of barrels neighboring D1.

\section{Controls}

In order to compare results from different groups of animals, control and D1-spared rats were maintained in approximately the same anesthetic state by using supplemental doses of urethane as required. The main criterion for judging the anesthetic state was the rate at which layer $\mathrm{V}$ cells fired bursts of spikes. Layer $V$ cells were sampled at the end of each penetration and the number of bursts per second measured. Burst rates were kept within limits $(0.7-2.0 \mathrm{~Hz})$ to ensure a comparable anesthetic state existed for each animal (see.Materials and Methods).

To test whether a systematic difference existed between the anesthetic states of the control and D1-spared animals despite these precautions, the area of cortex, or cortical domain, driven by a deprived vibrissa (D2) was measured in the same animals in which the D1-domain was measured. In order to do this it was necessary to allow D2 to regrow 4-7 d before recording. This was done starting at no younger than $60 \mathrm{~d}$. The results are shown in Figure 4 . The area of the barrel field driven by stimulating the D2 vibrissa is approximately the same as that occupied by an "experienced" vibrissa in a normal animal (compare with Fig. 2 controls).

If ancsthetic levels had been systematically lighter in PO animals compared with controls, one would expect uniformly larger cortical domains for all the vibrissae in $\mathrm{PO}$ animals compared with controls. In contrast, only the D1 domain was larger in P0 animals and the D2 domain was unchanged. Therefore, as most of the cells that describe the D2 and the D1 domain are common to both, the enlarged D1 domain could not have been due to anesthesia differences. There is a relative difference between the cortical area occupied by the "experienced" D1 vibrissa and the "deprived" D2 vibrissa.

\section{Response magnitudes}

The magnitude of each cell's response to D1 stimulation was recorded. In a subset of animals, where the vibrissa were allowed to regrow, the responses to other vibrissae were also logged. The response magnitude was defined as the number of spikes evoked by 50 stimuli within a $5-50 \mathrm{msec}$ poststimulus time window (see Materials and Methods) in order to compare results with those obtained from a prinr study (Armstrong-James and Fox, 1987). 


\section{Principal Vibrissa.}

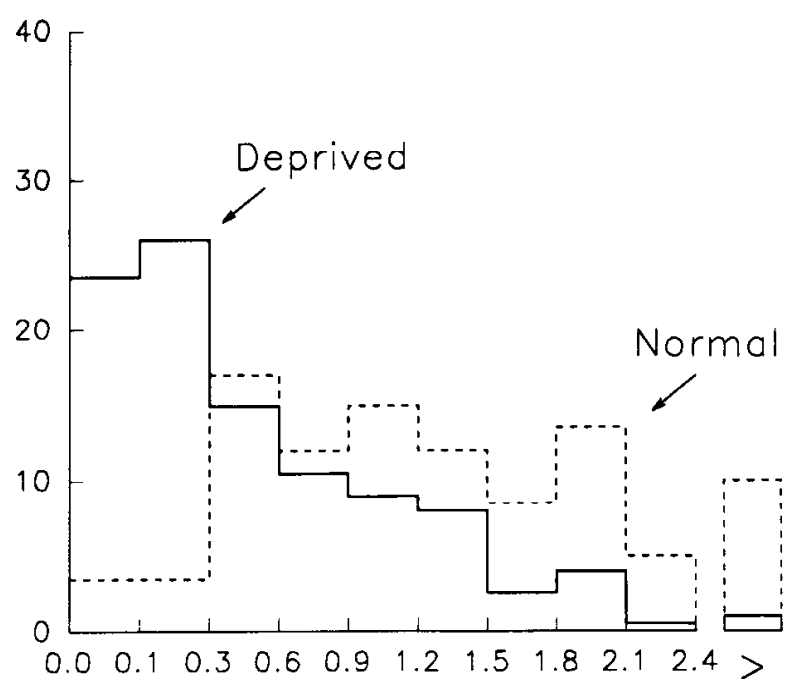

D1 Vibrissa

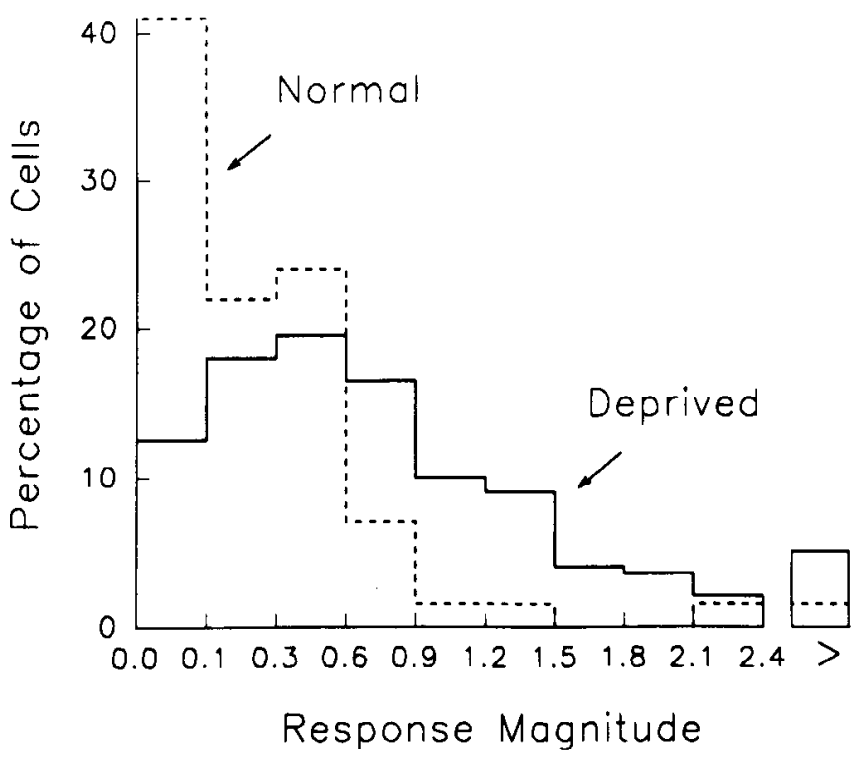

Figure 5. Effect of deprivation on absolute response magnitudes elicited by stimulation of the D1 and principal vibrissa in layers II/III. Top, The broken line shows the distribution of response magnitudes for 59 cells recorded from control animals in reply to stimulation of the principal vibrissa. The solid line shows the decrease in response magnitude for 207 cells recorded in D1-spared animals in reply to stimulation of their principal vibrissa (cells located in barrels neighboring D1 only). Bottom, The broken line shows the distribution of absolute response magnitudes for 54 cells located in barrels neighboring D1 in control animals. The solid line represents the increased response magnitudes for the DI vibrissa in barrels neighboring D1 in animals deprived of all but the D1 vibrissa $(n=207)$. Abscissa scale shows spikes per stimulus.

\section{Comparisons between D1-spared and normal animals}

In layer IV, uni-vibrissa rearing had a small effect on absolute response magnitudes to stimulation of principal or D1 vibrissae. Responses to principal vibrissa stimulation for cells located in barrels neighboring D1 showed a small but insignificant decrease compared with controls $(p>0.05$, Mann-Whitney $U$ test for large samples). There was, however, a small significant increase in the responses evoked by D1 in the same barrels compared with control $(p<0.05)$. In D1-spared animals $26 \%$ of the cells in barrels surrounding D1 responded with 0.9 spikes per stimulus or greater to D1 stimulation, compared with only $6 \%$ in normal animals (data not shown).

However, there were larger changes in absolute response magnitudes in layers II and III (Fig. 5). In control animals, response magnitudes evoked by stimulating the D1 vibrissa were low in barrels surrounding D1, with $42 \%$ not responding at all $(<0.1$ spikes per stimulus). The results were quite different for animals deprived of all but the $\mathrm{D} 1$ vibrissa from $\mathrm{P} 0$. In this case only $12.5 \%$ did not respond to D1 stimulation and $50 \%$ responded at greater than 0.6 spikes per stimulus compared with $13 \%$ in controls (see Fig. 5, bottom).

In addition to the increase in response to D1 stimulation, there was also a decrease in response to the principal vibrissa stimulation. For cells lying in barrels where the principal vibrissa had been deprived, $50 \%$ of the cells responded at less than 0.3 spikes per stimulus to principal vibrissa stimulation compared with $7 \%$ in control animals (Fig. 5, top). Both the increase in D1 responses and the decrease in principal vibrissae responses were highly significant $(p<0.001$, Mann-Whitney $U$ test) comparing distributions shown in Figure 5 .

In summary, the decrease in principal vibrissa input to deprived barrels was small and insignificant in layer IV but large and highly significant in layers II/III. The small increase in DI input into deprived barrels was small but significant in layer IV, and large and highly significant in layers II/III.

\section{Comparison within D1-spared and normal animals}

Part of the reason for the wide range in absolute response magnitudes to vibrissae stimulation could stem from small differences in anesthetic state and local condition of the cortex from cell to cell. In order to control for these possible variables, the relative responses of individual cells to the D1 vibrissa and the principal vibrissa, $F$, were calculated (see Materials and Methods). In this way each cell becomes its own control.

The results are shown for control animals in Figure 6. Layer II/III and layer IV results are presented separately. For control animals nearly all values of $F$ lie between zero (complete dominance by the principal vibrissa and no input from D1) and 0.5 (equal responses evoked by D1 and the principal vibrissa). Note that the D1 vibrissa rarely produces a greater response than the principal vibrissa in layers II/III and IV. The result is different for recordings from the P0 deprived animals as shown on the left of Figure 6. In this case many cells in layers II/III and IV respond to $\mathrm{D} 1$ with greater responses than they do to the principal vibrissa (i.e., $F>0.5$ for many cells). Approximately $37 \%$ of the cells in layer IV and $62 \%$ of the cells in layers II/III of barrels adjacent to DI are dominated by the D1 input. Fssentially the dominant vibrissa has changed for these cells from the one predicted by their anatomical location to the only vibrissa spared deprivation, D1.

\section{Critical period for deprivation}

The basic methodology described above for imposing and assessing the effects of uni-vibrissa rearing were used to determine its critical period by starting the deprivation at progressively later and later ages. A total of 614 cells were recorded from 142 penetrations in animals deprived from P2 (48 hr), P4, and P7. The results of response magnitude analysis are shown in Figure 


\section{CONTROLS}
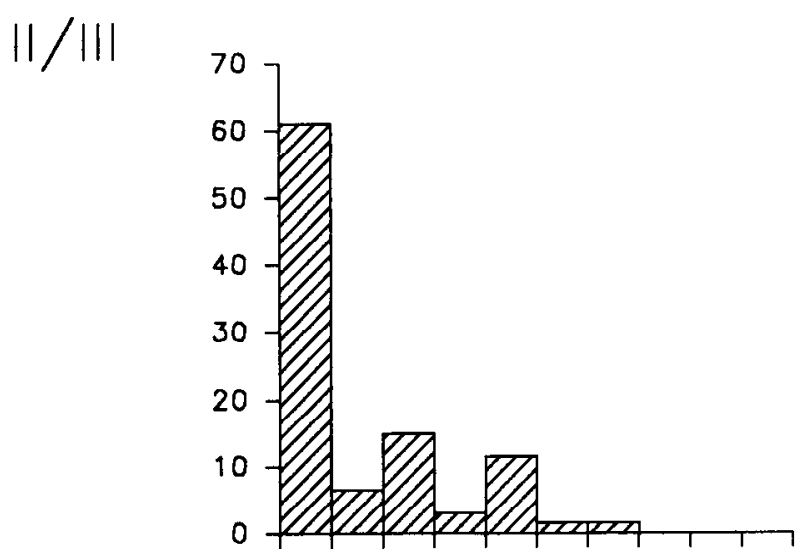

IV

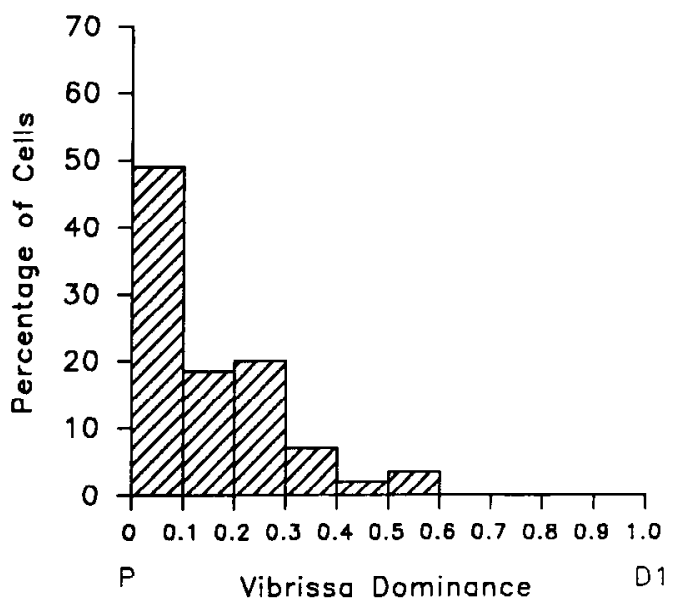

DEPRIVED (PO)
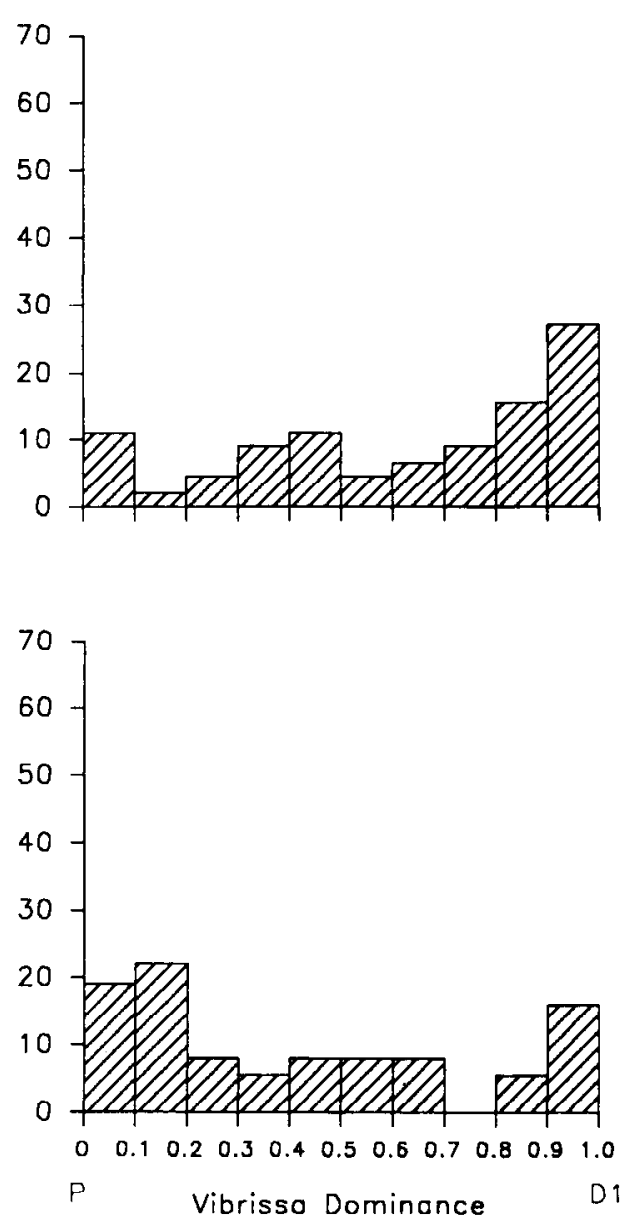

Figure 6. Effect of deprivation on dominance of principal vibrissa. Left, In normally reared animals, most cells are dominated by their principal vibrissa, as can be seen from the skew of the distribution to the left of the graph. The top graph is for layer II/III cells (77 cells), and the lower graph, for layer IV (60 cells). Right, In animals reared with just D1 from P0, many cells become dominated by D1 rather than their principal vibrissa. The effect is greater in layers II/III ( 113 cells) than in layer IV (108 cells). See Materials and Methods for definition of $F$.

7. For layer IV cells, there is a gradual shift of the distribution toward the left of the graph (i.e., toward a control distribution) with progressively later onset of deprivation. By P4 the layer IV distribution is significantly different from that at $\mathrm{P0}$ and $\mathrm{P} 2$ ( $p<0.01$, Mann-Whitney $U$ test) but has not returned completely to control values either (see Fig. 6). The distribution moves no further toward control with the P7 age group, which has a histogram similar to the P4 group.

Plasticity of cells in layers II and III assessed by the distribution of $F$ remains relatively constant up to and including $\mathrm{P} 7$, following an initial drop between $\mathrm{P0}$ and $\mathrm{P} 2$. The histograms for layers II/III are relatively flat, with just over $50 \%$ of the cells responding preferentially to the D1 vibrissa at all ages. Since the plasticity shown by layer IV is decreasing over the same age range, the degree of $\mathrm{D} 1$ dominance is different between layers in the same animals, and this difference could often be seen in a single penetration.

The difference in plasticity between layers II/III and IV was particularly prominent for animals deprived of all but the D1 vibrissa heginning at $\mathrm{P} 4$ and $\mathrm{P} 7$. In 24 of 64 penetrations, responses switched from D1 in superficial layers to the principal vibrissa in deeper layers. Figure 8 shows the responses of cells encountered in a single penetration centered on the D2 barrel in an animal deprived from P7. In superficial layers, responses to D1 predominate, which is indicated by the fraction D1/(D1 + D2) (i.e., $F$ ), being between 0.5 and 1 for the first $400 \mu \mathrm{m}$ (Fig. 8, right). As the layer III/IV border is approached, responses to the principal vibrissa increase until in layer IV itself only the principal vibrissa drives the cell. The latencies of response for the two vibrissae also switch over, with the fastest responses to D1 occurring in superficial layers (9-12 msec) and slowest in layer IV (17-26 msec), whereas for D2 stimulation the fastest responses are located in layer IV $(6-13 \mathrm{msec})$, and the slowest, in superficial layers (14 msec).

These results indicate a failure in vertical transmission from cells in layer IV responding to deprived vibrissae to cells immediately superficial to them. The input from the D1 vibrissa to the cells in superficial layers is most likely to have originated lateral to the column in which the cells are located.

\section{Summary of critical period}

Plasticity appears to decrease rapidly in layer IV between P0 and $\mathrm{P} 4$ as judged by the proportion of cells dominated by the "experienced" D1 versus the "inexperienced" principal vibrissa 

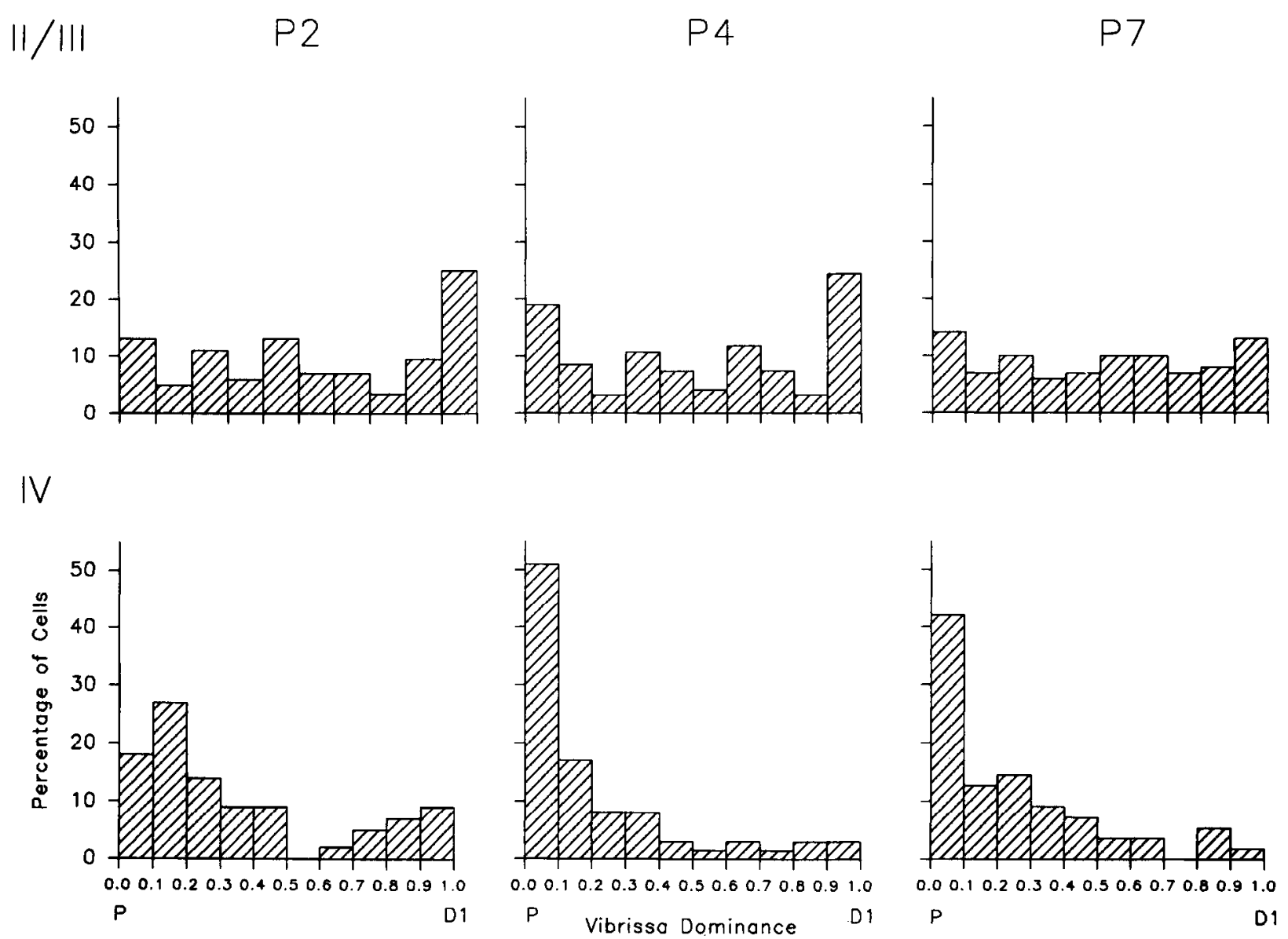

Figure 7. Effect of delaying the start of deprivation. Vibrissae dominance histograms are plotted for deprivations induced at three ages, P2 (left), P4 (center), and P7 (right). See Figure 6 for details. Note that in layer IV (lower row of graphs) the distribution shifts left toward the control distribution at P4 (compare wilth Fig. 6). In layers II/III (top row of graphs) there is little change with increasing delay in deprivation onset. Histograms are composed of, for P2, 130 cells in layers II/III and 65 in layer IV; for P4, 144 cells in layers IV/III and 125 layer IV; and for P7, 92 cells in layers II/III (P7) and 55 in layer IV.

in barrels immediately neighboring the D1 barrel. Figure 9 shows that this decrease in plasticity sees no further decline by P7. A similar conclusion is reached if one charts the decrease in the percentage of cells showing short-latency responses to D1 in neighboring barrels. Fast responses comprise $30 \%$ of the total in P0 deprived animals and $18 \%, 13 \%$, and $15 \%$ in P2, P4, and P7 deprived animals, respectively.

Latency analysis was less predictive of plasticity in superficial layers due to the large range of latencies in the population, but if the relative magnitude $(F)$ of $\mathrm{Dl}$ versus principal vibrissae responses are plotted against age of deprivation onset, very little change is seen between $\mathrm{P} 0$ and $\mathrm{P} 7$, apart from a small drop occurring between $\mathrm{P} 0$ and $\mathrm{P} 2$.

Since the proportion of cells dominated by the "wrong" vibrissa in control animals is low, these results show that the critical periods for layers II, III, and IV have not ended by P7. However, synaptic plasticity shows a large decline in layer IV between $\mathrm{P} 0$ and $\mathrm{P} 4$ at a time when synaptic plasticity is relatively constant in layers II and III. These data suggest that the critical period in layers II and III outlasts that in layer IV.

\section{Discussion}

Topological maps of the periphery are established early on in the development of sensory cortex (Rubel, 1971; ArmstrongJames, 1975; Braastad and Heggelund, 1985; Dawson and Kil- lackey, 1985). At birth the rat cortex is in a relatively undeveloped state, making possible the study of map development and the influence of experience on its final form. Former studies have shown that the major features of the somatotopic map are formed within the first week of life (for review, see Killackey et al., 1990). The thalamocortical afferents cluster into barrels over the first 4 or $5 \mathrm{~d}$ (Erzurumlu and Jhaveri, 1990), and the cortical cells in layer IV form into the characteristic cell sparse hollows and cell-dense barrel walls during the same period (Rice et al., 1985).

In order to disturb these large-scale features during development, a fairly severe intervention is required, such as lesioning vibrissae follicles or cutting the infraorbital nerve (Killackey et al., 1976; Jeanmonod et al., 1981). In this study, it was found that a relatively mild form of deprivation (pulling out vibrissae) was sufficient to alter the connectivity of the barrel cortex but insufficient, in general, to alter the larger features of cortical somatotopic organization. In a minority of animals deprived at P0, the D1 barrel was slightly enlarged, but this was a minor change compared with the degree to which physiologically defined boundaries of the D1 domain expanded.

The changes seen were remarkable considering that the form of deprivation employed is unlikely to abolish activity in the deprived pathways. Pulling out vibrissae presumably reduces the amount of activity in the pathways with which they are 


\section{Depth Profile for Penetration through D2 Barrel in a P7 Deprived Animal.}

\author{
Relative Response \\ Magnitude.
}

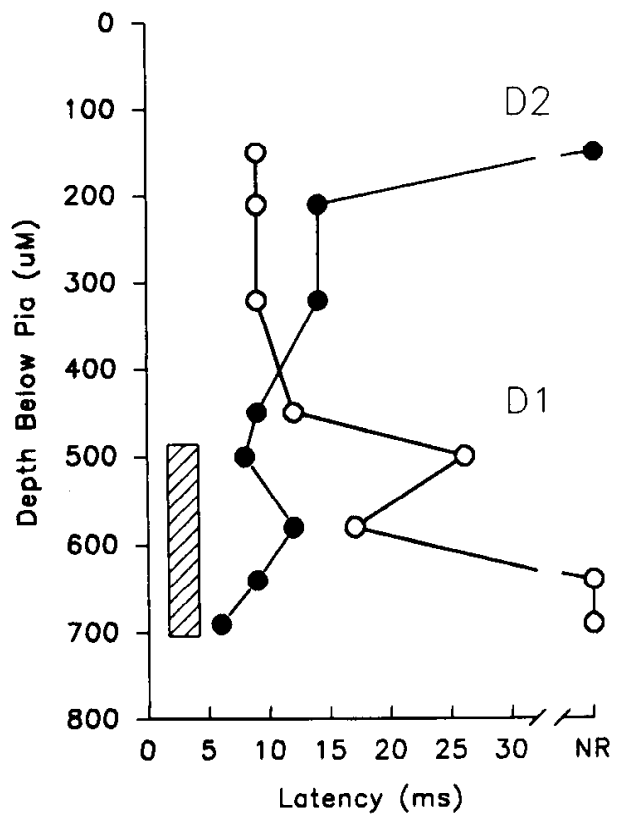

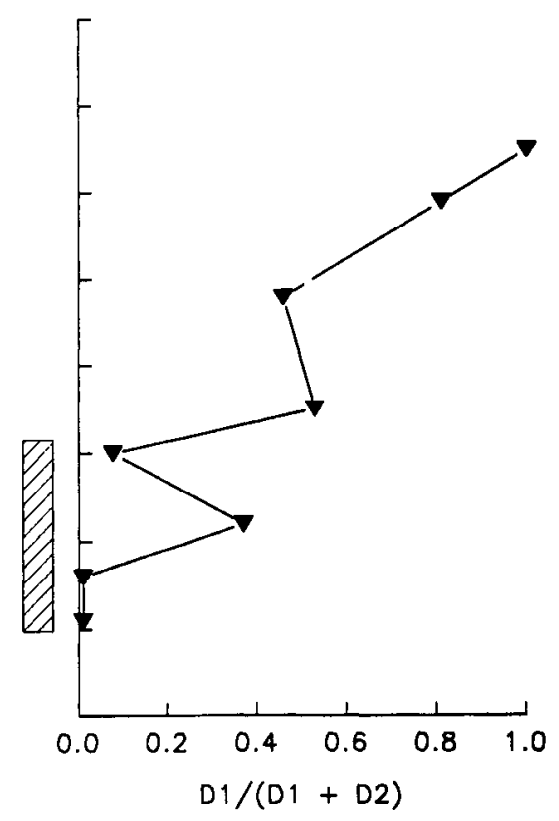

Figure 8. Effect of deprivation as a function of cortical depth. Data are plotted for recordings made from eight cells in a single penetration through the center of the D2 barrel. Left, Modal response latency is plotted against depth below pia in microns (depth confirmed from lesion location postmortem). The D2 vibrissa evokes short-latency responses at deeper locations (solid circles) and, the D1 vibrissa, shorter-latency rcsponses at more superficial locations (open circles). The shaded bar marks the location of $\mathrm{CO}$ staining of the D2 barrel. Right, The relative response magnitude for $D 1$ versus $D 2$ (the principal vibrissa for the D2 barrel) plotted for the same cells as shown to the left (see Results for description). associated. However, as the follicle is left intact along with the attendant nerve endings, activity in the primary afferents, whether spontaneous or caused by whisking or nuzzling, is likely to propagate through to the cortex.

The procedure for extracting vibrissae was designed not to cause damage to the follicles and nerve endings. That this was successful is evident from the ability to evoke responses in cortex by direct tactile stimulation of the empty follicles or, having allowed them to regrow for a few days, the vibrissae (see Fig. 4 for example). It is possible that partial damage occurred, however, and that the damage repaired during the 4-7 d allowed for regrowth; this is under investigation.

It is possible that some high-threshold C-fiber activity was evoked during pulling out the vibrissae. Decreasing unmyelinated fiber activity chronically (Wall et al., 1982) or acutely (Calford and Tweedale, 1991) increases receptive field size in cortex. Theoretically, increasing unmyelinated fiber activity, by pulling out vibrissae, might therefore reduce the representation of the deprived vibrissae. However, it seems far more likely that the altered balance of normal sensory experience is the cause of plasticity, given the brevity of the opportunity for nociceptor activation compared with the long periods of days and weeks when only the D1 vibrissa was available for sensation. Furthermore, the effect of capsaicin is to act at the brainstem level (Wall et al., 1982), and many of the effects seen in this study cannot be explained at this level (see below).

In the studies of Hand (1982) and Simons and Land (1987), the vibrissae were trimmed rather than pulled out. The disadvantage of trimming is that it needs to be repeated every day, whereas the technique used here need only be performed every

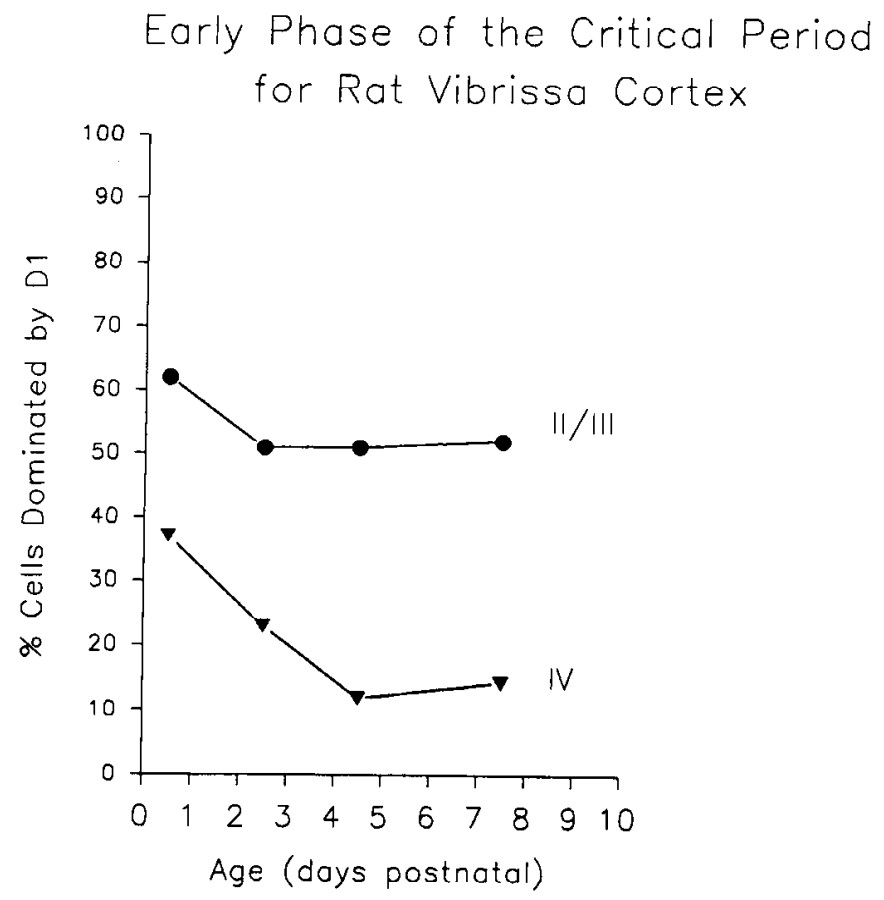

Figure 9. The early phase of the critical period for deprivation in rat vibrissa cortex. Points represent the percentage of cells in barrels surrounding D1 dominated by the D1 vibrissa (i.e., all cells where the D1 input is greater than the principal vibrissa input, $F=0.5-1.0$ ). The data are plotted separately for layers II/III (circles) and layer IV (triangles) versus age at onset of deprivation. 
other day (which is not a trivial saving). Techniques that cause damage lead to morphological changes in layer IV, yet in both this study (in 2 out of 3 of P0 and in all of P2-P7 animals) and that of Simons and Land (1987) (all animals), physiological changes occurred in the absence of changes in the barrel field anatomy. This supports the idea that our technique for extracting vibrissae works in the same way as vibrissae trimming, that is, by affecting activity. If the plasticity seen in this study had been caused by damaging nerve fibers, it is unlikely that it would have shown a critical period. Cortical plasticity induced by lesions does not show a critical period, but can be demonstrated in the somatosensory (Merzenich et al., 1983) and visual cortex (Kaas et al., 1990) of adult animals. However, plasticity caused by altering the balance of afferent activity transmitted along intact pathways to the cortex does show a critical period (Olson and Freeman, 1980). Since cortical responses showed a critical period in this study, this suggests that our deprivation paradigm acts by altering the balance of activity levels rather than anything else.

\section{The locus of plasticity}

It can be argued that the short-latency responses seen in layer IV are due to monosynaptic excitation from the thalamus. This argument is consistent with the idea that the lemniscal pathway provides the fastest transmission route to the cortex and in addition explains two observations; first, it explains why shortlatency responses are confined to the area occupied by the thalamocortical afferents in normal animals. Second, it explains the decreasing probability of finding short-latency responses outside the principal barrel as deprivation is started further into completion of thalamocortical afferent segregation.

The ability of activity to influence somatotopy in layer IV of the cortex was found to decrease dramatically between $\mathrm{P} 0$ and $\mathrm{P} 4$, which is precisely the same time over which thalamocortical afferents are segregating in layer IV to form the barrels (Erzurumlu and Jhaveri, 1990; Senft and Woolsey, 1991). An explanation for the widespread distribution of short-latency responses found in barrels neighboring D1 would therefore be that they are due to thalamocortical afferents, which were not induced to segregate normally due to the deficit of activity in the pathways associated with the deprived vibrissae. This is a similar form of explanation to that proposed for development of ocular dominance patches in layer IV of visual cortex (Hubel et al., 1977), where initially overlapping geniculocortical afferents segregate out into roughly equal sets of right and left eye domains. An imbalance of activity between the eyes can cause unequal segregation to the benefit of the "experienced" eye.

In these experiments a large discrepancy was found between the capacity for synaptic plasticity in layer IV compared with layers II and III. Synaptic plasticity was greater in layers II/III than IV at all ages studied. Using the 2-deoxyglucose (2-DG) technique, Hand (1982) also noted larger changes in layers II and III versus layer IV of somatosensory cortex in animals with follicle lesions. However, a similar increase in layer II/III metabolism was not seen with vibrissa-trimmed animals. This could be due to a lesser sensitivity in the 2-DG technique for detecting changes compared with the single-cell recording methods used here.

After a small decrease between $\mathrm{P} 0$ and $\mathrm{P} 2$, no further change was seen in plasticity of layers II and III between P2 and P7. The fact that the critical period for supragranular layers outlasts that of granular layers may be a general feature of cortical or- ganization. In cat visual cortex, monocular deprivation causes plasticity in extragranular layers that ends later than that in layer IV (Fox et al., 1989; Daw et al., 1992). Because the major source of synaptic input to layers II and III is intracortical, deprivations affecting just layers II and III must represent cortical plasticity. The main locus of plasticity in the animals deprived from P4 and P7 onward is therefore not subcortical but cortical.

The identity of the pathways responsible for plasticity manifested in layers II and III is unknown. By some route, excitation must travel horizontally to affect cells in layers II and III over a large radius. It is known that tactile information is transmitted horizontally in barrel cortex even in normal animals (Armstrong-James and Fox, 1987). A single barrel appears to provide the original source for subsequent spread of responses within the cortex, both from latency considerations (Armstrong-James and Fox, 1987) and lesion studies (Armstrong-James et al., 1991). Presumably the same pathways involved in normal horizontal transmission are enhanced in uni-vibrissa animals to produce more secure transmission of $D 1$ vibrissa information. The most likely routes are via the horizontal connections in layers II/III and layer $\mathrm{V}$.

\section{Mechanisms for plasticity}

If we accept the argument that altered sensory activity causes cortical plasticity, we are left with the fundamental question of whether it requires postsynaptic activity of cortical neurons. The reason for questioning whether postsynaptic activity can influence development and plasticity in the first postnatal week is that synaptic transmission is very immature at this stage. Afferents from the thalamic ventroposterior medial nucleus (VPm; Erzurumlu and Jhaveri, 1990; Senft and Woolsey, 1991) and synapses (Kristt and Molliver, 1975) are present in the cortex as early as P0. However, the number of excitatory synapses, the number and size of vesicles in synapses, and the levels of excitatory amino acid transmitter present in the first week of cortical maturation are extremely low, even by comparison with the second and third weeks (Armstrong-James and Johnson, 1970; Johnson and Armstrong-James, 1970; Blue and Parnavelas, 1983; Kvale et al., 1983). The first age at which somatosensory responses can be recorded in rats is P7. At this age responses fatigue easily, requiring stimulus rates of 1 every 15 $\mathrm{sec}$ for adequate responses (Armstrong-James, 1975). In slices of mouse cortex it is possible to evoke EPSPs by electrical stimulation of VPm as early as P0 in layers V and VI ( $\mathrm{P} 3$ in layer IV), but it is unknown whether natural stimulation evokes EPSPs in animals this young (Agmon et al., 1990). Natural stimulation does produce diffuse 2-DG uptake as early as $\mathrm{P} 2$ in the rat cortex (Kossut and Hand, 1984), but this is not known to be postsynaptic or related to depolarization.

Despite these arguments, there are some features of immature cortex that could explain how postsynaptic activity might occur in the first week. First, there is an absence of type II inhibitory synapses, and a prevalence of NMDA receptors at this age (Blue and Parnavelas, 1983; Insel et al., 1990). The absence of inhibitory effects is known to enhance NMDA-mediated activity in young rat somatosensory cortex (Luhman and Prince, 1990). Second, even if presynaptic release is low in the first week, NMDA receptors have a higher affinity for glutamate than the nonNMDA receptors prevalent in mature cortex (Olverman et al., 1988; Inscl ct al., 1990; Patneau and Mayer, 1990). Lastly, it is known that NMDA receptors can be activated by low levels 
of sensory input even in adult animals (Fox et al., 1990), where inhibitory effects reduce NMDA channel activity (Luhman and Prince, 1990). Taken together, these factors could explain how postsynaptic depolarization is generated in immature cortex.

As has often been pointed out in the literature, the advantage of the postsynaptic element being decisive in sorting afferents is that it provides a Hebbian mechanism for selecting correlated inputs. Such a mechanism could sort the thalamocortical axons responding to individual vibrissae into barrels. In this regard, whisking must cause highly correlated discharges in the afferent pathways from the vibrissae. If the degree of correlated activity is important in setting up somatotopic relations, as it appears to be for setting up retinotopic and binocular relations (Stryker, 1986; Cline and Constantine-Paton, 1989), whisking would be expected to have a deleterious effect on separation of vibrissa representations. However, we noticed that whisking did not occur until P10-P12 in the seven litters reared for this study, which is similar to estimates that normal whisking behavior appears by P15-P17 in albino rats (Welker, 1964). Therefore, whisking appears to begin too late to have an influence on barrel formation, or on the plasticity reported here.

The mechanisms by which cortical domains are formed appear to be competitive, at least in layers II/III, as there was not only an increase in the "experienced" D1 vibrissa inputs to deprived barrels, but also a decrease in the principal vibrissa input to the same barrels. In layer IV, the responses caused by the principal vibrissa input were not significantly different between normal and D1-spared animals. Since the principal vibrissa input to layers II/III above was greatly reduced, this implies a breakdown in vertical transmission of principal vibrissa information within the cortex in D1-spared animals.

In an earlier study an increase in the principal vibrissae inputs to layer IV cells in deprived barrels was observed (Simons and Land, 1987). This was not confirmed in this study, but if so it would make the loss of principal vibrissa input to layers II/III even more pronounced. It is possible that the reason for the discrepancy arises from the vibrissae only being allowed to regrow for 4-7 $\mathrm{d}$ in this study versus $3-15$ weeks in the other. Three to 15 weeks might allow time for recovery of synaptic transmission in layer IV.

\section{Correlates of the critical period}

One of the advantages of plotting the critical period is that it allows comparison with factors that may be involved in plasticity. For example, a number of transmitter systems show a transient development in the rat barrel cortex. The appearance of 5-HT axons in barrel cortex at around Pl coincides with the start of barrel formation (Rhoades et al., 1990). AChE staining in layer IV also appears at about the same time (Kristt, 1979). Both systems are therefore present during the critical period for layer IV. As neither system is present in layers II and III, however, which also exhibit plasticity at this and later ages, their influence appears more specialized than in gating cortical plasticity.

Stress-induced glucocorticoid release is inhibited during early development in the rat (Sapolsky and Meaney, 1986). This period, lasting from $\mathrm{P0}$ to about P15-P20 also covers the period during which plasticity was observed in the cortex in this study. Since glucocorticoids inhibit development (Schapiro et al., 1973; Sapolsky and Meaney, 1986) and reduce plasticity (Daw et al., 1991), their downregulation during this period may be involved in gating plasticity.
The event most highly correlated with the decrease in plasticity in layer IV is formation of the thalamocortical axon arbors into barrels (Erzurumlu and Jhaveri, 1990). There is also evidence that intracortical projections start off more diffusely distributed in extragranular layers (Nicolelis et al., 1991). The period over which they become refined is roughly P14-P21. If segregation is a major determinant of the critical period in extragranular layers as well, this predicts that the critical period in layers II/III, which shows little sign of decreasing at the end of the first postnatal week, might have decreased considerably by the end of the third week.

\section{References}

Agmon A, O'Dowd DK, Jones EG (1990) Development of thalamocortical responses in barrel cortex of early postnatal mice. Soc Neurosci Abstr 16:631.

Armstrong-James M (1975) The functional status and columnar organization of single cells responding to cutaneous stimulation in neonatal rat somatosensory cortex. J Physiol (Lond) 246:501-538.

Armstrong-James M, Fox K (1987) Spatio-temporal convergence and divergence in the rat S1 'barrel cortex.' J Comp Neurol 263:264-281.

Armstrong-James M, Fox K (1988) A role for NMDA receptors in slow wave sleep. Brain Res 451:189-196.

Armstrong-James M, Fox K (1990) Intra-columnar and interlaminar relay of vibrissal information in barrel field cortex. Soc Neurosci Abstr 16:1215.

Armstrong-James M, Johnson R (1970) Quantitative studies of postnatal changes in synapses in rat superficial motor cerebral cortex. $Z$ Zelforsch Mikrosk Anat 110:559-568.

Armstrong-James M, Fox K, Millar J (1980) A method for etching the tips of carbon fire microelectrodes. J Neurosci Methods 2:431432.

Armstrong-James M, Callahan CA, Friedman MA (1991) Thalamocortical processing of vibrissal information in the rat. I. Intracortical origins of surround but not center-receptive fields of layer IV neurones in the rat $\mathrm{S} 1$ barrel field cortex. J Comp Neurol 303:193-210.

Blue ME, Parnavelas JG (1983) The formation and maturation of synapses in the visual cortex of the rat. II. Quantitative analysis. J Neurocytol 12:697-712.

Braastad BO, Heggelund P (1985) Development of spatial receptive field organization and orientation selectivity in kitten striate cortex. J Neurophysiol 53:1158-1178.

Calford MB, Tweedale R (1991) C-fibers provide a source of masking inhibition to primary somatosensory cortex. Philos Trans R Soc Lond [Biol] 243:269-275.

Chrapman B, Jacobson MD, Reiter HO, Stryker MP (1986) Ocular dominance shift in kitten visual cortex caused by imbalance in retinal electrical activity. Nature 324:154-156.

Cline HT, Constantine-Paton M (1989) NMDA receptor antagonists disrupt the retinotectal topographic map. Neuron 3:413-426.

Daw NW, Sato H, Fox K, Czepita D, Gingerich R (1991) Cortisol reduces plasticity in cat visual cortex. $J$ Neurobiol 22:158-168.

Daw NW, Fox K, Sato H, Czeptia D (1992) The critical period for plasticity in cat visual cortex. J Neurophysiol 67:in press.

Dawson DR, Killackey HP (1985) Distinguishing topography and somatotopy in the thalamocortical projections of the developing rat. Dev Brain Res 17:309-313.

Erzurumlu RS, Jhaveri S (1990) Thalamic axons confer a blueprint of the sensory periphery onto the developing rat somatosensory cortex. Dev Brain Res 56:229-234.

Fox K, Daw N, Sato H (1989) Plasticity in adult and adolescent cat visual cortex. Soc Neurosci Abstr 15:796.

Fox K, Sato H, Daw NW (1990) The effect of varying stimulus intensity on NMDA-receptor activity in cat visual cortex. J Neurophysiol 64:1413-1428.

Hamori J, Savy C, Madarasz M, Somogyi J, Tacaks J, Verley R, FarkasBargeton E (1986) Morphological alterations in subcortical vibrissal relays following vibrissal destruction at birth in the muuse. J Cump Neurol 254:166-183.

Hand PJ (1982) Plasticity of the rat cortical barrel system. In: Changing concepts of the nervous system (Morison AR, Strick PL, eds), pp 4968. New York: Academic. 
Hubel DH, Wiesel TW, LeVay S (1977) Plasticity of ocular dominance columns in monkey striate cortex. Philos Trans R Soc Lond [Biol] 278:377-409.

Insel TR, Miller LP, Gelhard RE (1990) The ontogeny of excitatory amino acid receptors in rat forebrain-I. $N$-methyl-D-aspartate and quisqualate receptors. Neuroscience 35:31-43.

Jeanmonod D, Rice FL, Van der Loos H (1981) Mouse somatosensory cortex: alterations in the barrelfield following receptor injury at different postnatal ages. Neuroscience 6:1503-1535.

Johnson R, Armstrong-James MA (1970) Morphology of superficial postnatal cerebral cortex with special reference to synapses. Z Zelforsch Mikrosk Anat 110:540-558.

Kaas JH (1991) Plasticity of sensory and motor maps in adult animals. Annu Rev Neurosci 14:137-167.

Kaas JH, Krubitzer LA, Chino YM, Langston AL, Polley EH, Blair EH (1990) Reorganization of cortical retinotopic maps in adult mammals after lesions of the retina. Science 248:229-231.

Killackey HP, Belford G, Ryugo R, Ryugo DK (1976) Anomalous organization of thalamocortical projections consequent to vibrissae removal in the newborn rat and mouse. Brain Res 104:309-315.

Killackey HP, Jacquin MF, Rhoades RW (1990) Development of somatosensory system structures. In: Development of sensory systems in mammals, Chap 10 (Coleman JR, ed), pp 401-430. New York: Wiley.

Kossut M, Hand P (1984) The development of the vibrissal cortical column: a 2-deoxyglucose study in the rat. Neurosci Lett 46:1-6.

Kristt DA (1979) Development of neocortical circuitry: histochemical localization of acetylcholinesterase in relation to the cell layers of rat somatosensory cortex. J Comp Neurol 186:1-16.

Kristt DA, Molliver ME (1976) Synapses in newborn rat cerebral cortex: a quantitative ultrastructural study. Brain Res 108:180-186.

Kvale I, Fosse VM, Fonnum F (1983) Development of neurotransmitter parameters in lateral geniculate body, superior colliculus and visual cortex in the albino rat. Dev Brain Res 7:137-145.

Luhman HJ, Prince DA (1990) Control of NMDA receptor mediated activity by GABA-ergic mechanisms in mature and developing rat neocortex. Dev Brain Res 54:287-290.

Merezenich MM, Kaas JH, Wall JT, Nelson RJ, Sur M, Felleman DJ (1983) Topographic reorganization of somatosensory cortical areas $3 \mathrm{~b}$ and 1 in adult monkeys following restricted deafferentation. Neuroscience 8:33-55.

Nicolelis MAL, Lin CS, Chapin JK (1991) Ontogeny of cortico-cortical connections of the rat somatosensory cortex. Somatosens Mot Res 8: 193-200.

Olson CR, Freeman RD (1980) Profile of the sensitive period for monocular deprivation in kittens. Exp Brain Res 39:17-21.

Olverman HJ, Jones AW, Mewet KN, Watkins JC (1988) Structure activity relations of $N$-methyl-D-aspartate receptor ligands as studied by their inhibition of [ $\left.{ }^{3} \mathrm{H}\right] \mathrm{D}$-2-amino-5-phosphonopentanoic acid binding in rat brain membranes. Neuroscience 26:17-31.

Patneau DK, Mayer ML (1990) Structure-activity relationships for amino acid transmitter candidates acting at $N$-methyl-D-aspartate and quisqualate receptors. J Neurosci 10:2385-2399.

Ramoa AS, Paradiso MA, Freeman RD (1988) Blockade of intra- cortical inhibition in kitten striate cortex: effects on receptive field properties and associated loss of ocular dominance plasticity. Exp Brain Res 73:285-296.

Rhoades RW, Chiaia NL, Mooney RD, Klein BG, Renehan WE, Jacquin MF (1987) Reorganization of the peripheral projections of the trigeminal ganglion following neonatal transection of the infraorbital nerve. Somatosens Mot Res 5:35-62.

Rhoades RW, Bennet-Clarke CA, Chiaia NL, White FA, MacDonald GJ, Haring JH, Jacquin MF (1990) Development and lesion induced reorganization of the cortical representation of the rat's body surface as revealed by immunocytochemistry for serotonin. J Comp Neurol 293:190-207.

Rice FL, Gomez C, Bartow C, Burnet A, Sands P (1985) A comparative analysis of the development of the primary somatosensory cortex: interspecies similarities during barrel and laminar development. J Comp Neurol 236:447-495.

Rubel EW (1971) A comparison of somatotopic organization in sensory cortex of newborn kittens and adult cats. J Comp Neurol 143: 447-480.

Sapolsky RM, Meaney MJ (1986) Maturation of the adrenocortical stress response: neuroendocrine control mechanisms and the hyporesponsive period. Brain Res Rev 11:65-76.

Schapiro S, Vukovich K, Globus A (1973) Effects of neonatal thyroxine and hydrocortisone administration on the development of dendritic spines in the visual cortex of rats. Exp Neurol 40:286-296.

Senft SL, Woolsey TA (1991) Growth of thalamic afferents into mouse barrel cortex. Cereb Cortex 1:308-335.

Simons DJ, Land PW (1987) Early experience of tactile stimulation influences organization of somatic sensory cortex. Nature 326:694 697.

Stryker MP (1986) The role of neural activity in rearranging connections in the central visual system. In: The biology of change in otolaryngology (Rubin RJ, Water TR, Rubel EW, eds), pp 211-224. Amsterdam: Elsevier.

Waite PME, Cragg BG (1982) The peripheral and central changes resulting from cutting or crushing the afferent nerve supply to the whiskers. Proc R Soc Lond [Biol] 214:191-211.

Wall PD, Fitzgerald M, Nussbaumer JC, Van der Loos $H$, Devor $M$ (1982) Somatotopic maps are disorganized in adult rodents treated neonatally with capsaicin. Nature 295:691-693.

Welker WI (1964) Analysis of sniffing of the albino rat. Behavior 22: 223-244.

Wiesel TW, Hubel DH (1963) Single cell responses in striate cortex of kittens deprived of vision in one eye. J Neurophysiol 26:10031017.

Wiesel TW, Hubel DH (1965) Comparison of the effects of unilateral and bilateral eye closure on cortical unit response in kittens. J Neurophysiol 28:1029-1040.

Wong-Riley MTT (1979) Changes in the visual system of monocularly sutured or enucleated cats demonstrable with cytochrome oxidase histochemistry. Brain Res 171:11-28.

Woolsey TA (1991) Peripheral alterations and somatosensory development. In: Development of sensory systems in mammals, Chap 12 (Coleman JR, ed), pp 461-503. New York: Wiley. 